\title{
CREDIBILIDAD: PRESUPUESTO NECESARIO PARA EL ENDEUDAMIENTO PÚBLICO
}

Lenin José Andara Suárez ${ }^{1}$

Profesor de Finanzas Públicas y Derecho Financiero. Universidad de Los Andes (ULA). Mérida, Venezuela.

1 Doctor por la Universidad de Salamanca, España, programa "Administración, Hacienda y Justicia en el Estado Social”, Diploma de Estudios Avanzados en Derecho Financiero y Tributario por la citada universidad. Ha escrito los libros: Poder y potestad tributaria. Acerca de las competencias tributarias en la República Bolivariana de Venezuela (2010), Ingreso, gasto y presupuesto público en el ordenamiento jurídico venezolano (2011), El presupuesto público venezolano (2012), El acto de liquidación tributaria. La determinación por la administración tributaria (2013), y, La autoliquidación y su incidencia en el sistema de aplicación de los tributos en España (2018), así como artículos científicos en revistas especializadas. Conferencista. Asesor. Investigador. 


\section{INTRODUCCIÓN}

Los sujetos que invierten en deuda pública lo hacen, generalmente, con la finalidad de obtener un beneficio, ello varía según se trate de un particular o de una entidad internacional; estos últimos pueden tener también otros intereses, incluso geoestratégicos en la concesión de créditos públicos. En todo caso, el fundamento de desembolsar cuantiosas cantidades de dinero tiene como lógica la obtención del beneficio económico y la devolución del dinero prestado; es eso lo que corresponde en el Estado de Derecho y las relaciones financieras internacionales.

La inversión en deuda pública conlleva asumir un riesgo pues se entiende que existe la posibilidad que un país no cumpla con sus obligaciones, específicamente estaríamos en presencia de un riesgo soberano, en el cual y a decir de SAMUELSON y NORDHAUS, debido a que el Estado es soberano y ejerce la última autoridad legal, no existe recurso alguno en el sistema legal ${ }^{2}$. Desde el punto de vista interno, estos créditos suelen ser inejecutables o sometidos a prerrogativas a favor del ente público que, normalmente, hacen infructuosa cualquier acción legal; desde el punto de vista externo, generalmente el país deudor carece de bienes suficientes para ejecutar semejantes montos y los que tiene, están protegidos por tratados internacionales por estar destinados a funciones diplomáticas; es posible también que posea bienes revestidos de personalidades jurídicas diferenciadas tal como sucede con empresas públicas, lo cual impide ejecutar decisiones judiciales al respecto. Este riesgo está latente en cada operación que realizan los inversionistas, sin embargo, lo asumen en sus diversos grados con la expectativa de obtener beneficios.

En el peor de los casos, aún cuando la posibilidad de incumplimiento aumenta, siempre existe la expectativa de obtener ganancias. Ello obedece en gran parte a la propia naturaleza del sistema con la que se configura la credibilidad como presupuesto necesario para el endeudamiento público.

\section{LA DEUDA PÚBLICA FORMA PARTE DEL ENTRAMADO PRESUPUESTARIO}

Hemos definido el presupuesto público como "el instrumento legal en el cual se realizan las estimaciones de ingresos que tendrá un ente público así como las autorizaciones para realizar gastos durante un tiempo determinado y a su vez constituye un instrumento de planificación de las políticas públicas con miras al cumplimiento de los fines del Estado" ${ }^{3}$ La deuda pública adquiere en los presupuestos nacionales un papel decisivo por su doble carácter, tanto de generador de ingresos como de gasto permanente.

2 SAMUELSON, P. y NORDHAUS, W. Economía. $18^{a}$ ed. Mc. Graw Hill, México, 2006, p. 265.

3 SUÁREZ, L. J. A. El presupuesto público venezolano. Universidad de Los Andes, Mérida, 2012, p. 31. 
Aún cuando tradicionalmente se atribuye al endeudamiento público un carácter excepcional, puede mantener dicha condición por imperio de disposiciones legales, si bien, desde el punto de vista económico, no lo sea. La fluidez con la que se produce la deuda pública es totalmente habitual y hoy día se consideran indispensables tanto las leyes aprobatorias del presupuesto público como las leyes autorizatorias de operaciones de endeudamiento público. Dentro de las clasificaciones del gasto público existe una que distingue entre gastos fijos y gastos variables; ya de antaño ORIA incluía en los gastos fijos la deuda pública, al señalar: "Se llaman gastos fijos los que se producen en los sucesivos presupuestos, por responder a una necesidad formal y constante y en cierto modo homogénea, como los que entraña la deuda pública, los correspondientes a sueldos y en general los de toda la administración pública"4, mantienen cifras o porcentajes relativamente constantes. RESTREPO ha resaltado que “en el manejo de las finanzas públicas modernas el recurso al crédito público es algo usual, prácticamente permanente, y los recursos obtenidos por este conducto no están necesariamente asociados al financiamiento de gastos excepcionales" ${ }^{5}$.

Desde el punto de vista financiero no cabe duda que gastos como el pago de intereses de la deuda pública forman parte de los gastos ordinarios. Tiene toda la caracterización que señala BAQUERO, es decir, "tiende a presentarse en cada ejercicio presupuestario de manera constante y periódica" ${ }^{6}$; contrario sensu se descarta su carácter accidental, esporádico o no periódico. Similar situación ocurre en su valoración como ingresos público, ya que desde este mismo punto de vista se trata de un ingreso ordinario. No obstante, la legislación puede atribuir un carácter extraordinario tanto al pago de deuda como al ingreso por endeudamiento público, todo ello con la finalidad de separarlos del régimen jurídico ordinario tanto de ingresos como de gastos.

El endeudamiento público es una figura paralela al presupuesto público y ninguno de estos instrumentos parece cumplir su función específica, sin desprenderse uno del otro. Con el presupuesto público se produce la ordenación de la actividad financiera del Estado, es permanente año tras año y en igual medida lo es el endeudamiento público.

\section{LA CREDIBILIDAD COMO SOPORTE DEL ENDEUDAMIENTO PÚBLICO}

El endeudamiento público está marcado por un elemento previo de tipo subjetivo constituido por la credibilidad que posee un Estado para cumplir con las

4 ORIA, S. Finanzas. Editorial Guillermo Kraft Ltda., Buenos Aires, 1948, p. 307.

5 RESTREPO, J. C. Hacienda Pública, $3^{a}$ ed. Universidad Externado de Colombia, Bogotá, 1996, p. 288.

6 BAQUERO, J. L. Lecciones de Finanzas Públicas y Derecho Fiscal, t. I, Paredes Editores, Caracas, 1989, p. 151. 
obligaciones que va a adquirir. Desde antiguo existe la idea que el crédito se vincula con la idea de creencia; ORIA señalaba que se traducía en dos formas: "la confianza o fe en la moral de una persona dispuesta a cumplir sus deberes y obligaciones, y la creencia de que podrá cumplirla por disponer de medios económicos"7. A partir de este planteamiento, el autor señala que el crédito público se mueve en "[e]l espíritu de especulación, la esperanza de una futura ganancia o enriquecimiento", propias de la forma capitalista.

El crédito público es identificado con la confianza que se tiene, o de la que disfruta un Estado de cumplir con sus obligaciones; se nutre de la posibilidad cierta de cumplir con las mismas. Ello da origen a definiciones de crédito público como la formulada por VILLEGAS cuando señala que es "la aptitud política, económica, jurídica y moral de un Estado para obtener dinero o bienes en préstamos" 8 . Nunca un Estado se ha encontrado tan cerca de ocupar una situación idéntica a la de un particular como sucede con el crédito público, y ello porque no podrá basarse en su ius imperium para imponer a los particulares el otorgamiento de un préstamo, ni para modificar unilateralmente las condiciones en las que fue adquirida la deuda pública; aunque ciertamente que al final del camino podría recurrir a esta opción pero ello iría claramente en contra del Estado de Derecho y acabaría o menoscabaría en gran medida la credibilidad que puede tener en los mercados de deuda pública con unas consecuencias difíciles de superar en el corto y mediano plazo.

Existe hoy día un reconocido carácter contractual del empréstito público, la voluntad del prestamista es fundamental para que el mismo sea otorgado, según el grado de credibilidad que tiene un inversionista en el ente público solicitante. Ha existido históricamente un tipo de empréstito de tipo forzoso, en el que no existe el consentimiento del acreedor; DUVERGER los ha llamado "empréstitos obligatorios" y EHEBERG, "empréstitos fiscales"; en ellos se produce una "requisición temporaria de capital" como lo señalaron ORIA y SAINZ DE BUJANDA; este último autor lo considera una "requisición temporal de capital en la que el Estado no utiliza su crédito, sino su poder de imperio"10. En la actualidad, esta figura parece desterrada de las Finanzas Públicas y del Derecho Financiero, cons-

7 ORIA, S. Finanzas..., ob. cit., p. 26.

8 VILLEGAS, H. Curso de finanzas, derecho financiero y tributario. $5^{\mathrm{a}}$ ed. Depalma, Buenos Aires, 1992, p. 759.

9 DUVerger, M. Hacienda Pública, $2^{a}$ ed. (Trad. Bagaria Perpiñá). Bosch, Barcelona, 1980, p. 124.

10 SAINZ DE BUJANDA, F. Lecciones de Derecho Financiero. Universidad Complutense, Madrid, 1993, p. 427. 
tituye una violación al derecho de propiedad, al menos en condiciones normales de institucionalidad y seguridad nacional. Sólo sería aplicable en el plano del derecho interno de un país pues resulta literalmente inimaginable que una medida de esta naturaleza pueda ser ejecutada en el plano internacional. Entiéndase pues que en la actualidad no hay lugar a la coacción a un sujeto para que realice un préstamo a favor de un ente público. En lugar de eso, la credibilidad y la voluntad del acreedor van a ser fundamentales.

El Diccionario de la Real Academia Española asigna a la palabra "credibilidad" la "cualidad de lo creíble". Mientras que el término "creíble" como un adjetivo que remite a lo “[q]ue puede o merece ser creído". En nuestra materia, debe ser creíble que el Estado va a cumplir con la deuda pública, y que va a cumplir exactamente en las condiciones pautadas en la emisión de deuda y suscritas por el acreedor.

Los elementos anteriores los encontramos presentes en las definiciones de crédito público señaladas por SAINZ DE BUJANDA, quien al respecto señala que con tal expresión "se alude a la posibilidad por parte de un ente público de aprovecharse de la confianza de que puede gozar por parte de otros sujetos de derecho (público o privado) para lograr los medios con que subvenir a sus necesidades ${ }^{11}$.

La credibilidad de un ente público para endeudarse va a depender de factores de diversa naturaleza y no surge de forma automática como resultado de una decisión unilateral del Estado, no surge de una ley, ni de un decreto. El convencimiento para otorgar los fondos a un ente público corresponde a los inversionistas, los convencidos deben ser los inversionistas y no el ente público que va a recibir los fondos.

La variedad de acreedores puede influir en una mayor dependencia a la credibilidad del país para el acceso al crédito. Los Estados y organizaciones internacionales pueden menospreciar el apoyo de los mercados financieros a determinado país y sumar apoyo financiero mediante la concesión de líneas de crédito supeditados a la implementación de medidas económicas, aperturas de mercados, beneficios fiscales, concesiones mineras o de otra índole, entre otras medidas. Se trata así de un respaldo político que lleva implícito otros intereses que dentro de la escena internacional puede obedecer a razones ideológicas y al interés de no permitir el descalabro de uno de los eslabones de los mercados financieros internacionales, lo cual puede traducirse en un efecto dominó. El propio respaldo de una potencia financiera puede drenar liquidez para que, a su vez, el Estado deu-

11 Ídem, p. 425. 
dor cumpla con sus acreedores otorgando un lapso de maniobrabilidad financiera en el que pueda restablecer un mínimo de condiciones para continuar operando en los mercados.

En estos casos, el respaldo político desplaza el concepto de "credibilidad" pues aunque el país no tenga las condiciones para cumplir con sus obligaciones financieras internacionales, recibe el apoyo de una potencia financiera o de una organización internacional a los fines de alcanzar un cierto grado de estabilidad. No obstante, puede persistir en última instancia un grado de credibilidad del país y ello debido a que se entiende que las condiciones del país deben mejorar a los fines de dar cumplimiento a las obligaciones adquiridas. Diferente es el caso que el crédito público internacional haya sido otorgado deliberadamente a sabiendas de su incumplimiento y a una necesidad permanente de reestructuración a los fines de evitar un default reconocido por la comunidad financiera internacional.

\section{EL ENDEUDAMIENTO PÚBLICO ES UN FENÓMENO ENDÉMICO}

La necesidad de poseer credibilidad para acceder al endeudamiento público es permanente, ello debido a que el endeudamiento público se ha convertido en un fenómeno endémico. CONTRERAS reconoce que "[e]s una práctica ampliamente extendida en el mundo moderno que los Estados gasten, en cada ejercicio, más dinero que el que recaudan debido a los compromisos políticos y sociales que asumen"12. El ejemplo más importante es la deuda pública de los Estados Unidos de América cuyos montos no dejan de alcanzar cifras records; este fenómeno tampoco para de crecer en ningún país del mundo, aunque el dólar americano, como moneda de reserva y de mayor uso internacional plantea una situación especial pues como afirmara Donald Trump en 2016, sobre la deuda de dicho país: "nunca hay por qué dejar de pagar porque eres tú el que imprimes el dinero, lamento decirles, ¿de acuerdo?"

Con ello queremos poner de relevancia que la situación financiera de un país latinoamericano no es la misma que la de los Estados Unidos de América (USA); todo ello ha de incidir en los esfuerzos que deben realizar los países emergentes para acudir en el competitivo mercado de la deuda pública. Y por ende, deben realizar mayores esfuerzos para disfrutar de la credibilidad de los inversionistas.

12 CONTRERAS DE USSCHER, I. Glosario y formulario de Administración Financiera. Universidad de Los Andes, Mérida, 2005, p. 83.

13 Donald Trump, Declaraciones para CNN con el presentador Chris Cuomo en el programa "New Day", 9 de mayo, 2016. [Disponible on line: http://cnnespanol.cnn.com/2016/05/09/ trump-ee-uu-nunca-dejara-de-pagar-su-deuda-porque-es-el-que-imprime-el-dinero/\#0]. 
Hoy día se analiza, entre otros aspectos, la relación que existe entre la deuda pública y el Producto Interno Bruto (PIB) de los países. Y allí reside una causa de preocupación para los órganos centrales, tal como sucede en Europa con la deuda de España cuya relación ha llegado a estar en más del 100\% del PIB. En los últimos años, los términos nominales la deuda de las Administraciones Públicas española es la siguiente:

\section{Cuadro 1: Deuda de las Administraciones Públicas españolas}

\begin{tabular}{|c|c|}
\hline Año & $\boldsymbol{\epsilon} \mathbf{~ m m}$. \\
\hline 2013 & $979.031,00$ \\
\hline 2014 & $1.041 .624,00$ \\
\hline 2015 & $1.073 .934,00$ \\
\hline 2016 & $1.107 .205,00$ \\
\hline 2017 & $1.144 .629,00$ \\
\hline
\end{tabular}

Fuente: Banco de España.

Otra preocupación que surge en estos casos es en qué medida una desproporción de deuda pública puede generar una desatención a gastos impostergables como salud, educación, seguridad y mantenimiento de infraestructuras, generando así tensiones sociales y políticas que pudieran llegar a afectar la credibilidad del país en el plano internacional, al verse afectada la estabilidad institucional de una nación.

\section{LAS GESTIONES DIPLOMÁTICAS NO GARANTIZAN EL COBRO DE UNA DEUDA PÚBLICA}

Otro factor que fortalece la necesidad de poseer credibilidad para acceder al endeudamiento público es la inexistencia de garantías ante un eventual incumplimiento. Se entiende que el incumplimiento puede ser de diversas modalidades si bien el de mayor gravedad es el incumplimiento total e indefinido.

Históricamente se puede encontrar en la literatura financiera referencias al "repudio de deuda", como acto en el que un Estado, según VILLEGAS "niega la obligación derivada del empréstito" 14 con lo que se traiciona la buena fe del prestamista. Como ejemplos, el autor señala: el repudio de deuda que hizo los Estados

${ }^{14}$ VILLEGAS, H. Curso..., ob.cit., p. 787. 
Unidos de "las deudas de los Estados Confederados luego de la guerra de secesión", asimismo el repudio que Inglaterra hizo de "las deudas de la República Sudafricana luego de la guerra anglobóer", y, finalmente, el caso de Rusia que "repudió las deudas contraídas por el zarismo luego de la revolución bolchevique”. Pero estos episodios son históricos y obedecieron a circunstancias muy excepcionales que si bien pueden producirse en esta época, es bastante improbable que sucedan; por ello, las excluimos del presente análisis.

En contraposición vamos a encontrar el incumplimiento de la deuda pública, cuyas consecuencias, ya hemos señalado "son siempre graves dado que el crédito se basa siempre en la confianza de los acreedores en la capacidad y voluntad de pago del Estado que emite la deuda; el mismo debe llegar a un mecanismo de pago para tener la posibilidad de acudir nuevamente a los mercados, una vez saneadas sus finanzas" 15 .

En estos casos tienen lugar las gestiones diplomáticas de los países de origen de los prestamistas, especialmente cuando se trata de bancos y fondos de inversión. Se trata de lo que DIEZ DE VELASCO llama "protección diplomática de las personas físicas y jurídicas", de ejercicio discrecional por parte del Estado. Distinto es el caso del uso de la fuerza para el cobro de deudas y uno de cuyos episodios históricos se ubica a finales de 1902 e inicios de 1903 cuando se produce un bloqueo naval a Venezuela por parte de Alemania, Gran Bretaña e Italia debido a deudas que dicho país mantenía con nacionales de esos países ${ }^{16}$.

La reacción diplomática estuvo a cargo de Luis María Drago, Ministro de Asuntos Exteriores de Argentina, señala DIEZ DE VELASCO, quien envía una Nota que debía ser transmitida al Secretario de Estado Norteamericano en la que se manifestaba “...el principio que la Argentina quisiera ver reconocido en que la deuda pública no pudiera provocar la intervención armada, ni mucho menos la ocupación militar del territorio de las naciones americanas por parte de una potencia de Europa" ${ }^{17}$. Con este episodio queda proscrito el uso de la fuerza para el cobro de deudas públicas, lo cual se corresponde con el artículo $2^{\circ}$ numeral $4^{\circ}$ de la Carta de las Naciones Unidas cuando señala que los miembros de dicha organización "en sus relaciones internacionales, se abstendrán de recurrir a la amenaza o al uso de la fuerza contra la integridad territorial o la independencia

15 SUÁREZ, L. J. A. Ingreso, gasto y presupuesto público en el ordenamiento jurídico venezolano. Tomo I. Editor-autor, Mérida, 2011, p. 317.

16 Ídem, p. 318.

17 DIEZ DE VELASCO, M. Instituciones de Derecho Internacional Público. Tomo I. $4^{\mathrm{a}}$ ed., Tecnos, Madrid, 1978, p. 337. 
politica de cualquier Estado, o en cualquier otra forma incompatible con los Propósitos de las Naciones Unidas".

Así pues, las gestiones diplomáticas que pudieran crear expectativas de un acreedor de deuda pública no son efectivas en tanto no se crea una situación jurídica diferente al vínculo obligacional que ya existe y cuyo origen no es negado por un Estado deudor. Se descarta así que pueda acudirse al uso de la fuerza para forzar el pago de deuda pública. Si esto es así, el interés del acreedor debe centrarse en la credibilidad que el país tenga, esa va a ser su mejor garantía de pago.

\section{SOLUCIONES FRAGMENTADAS Y HETEROGÉNEAS EN LA SOLUCIÓN DE CONTROVERSIAS}

LOCHAGIN sostiene una tesis bastante interesante y reveladora en cuanto al supuesto que estamos señalando. Para este autor, en las crisis internacionales de deuda pública que conducen a la necesidad de reestructuración, los criterios de solución de controversias, cuando existen, se presentan de forma fragmentada y heterogénea ${ }^{18}$. Si ello es así, no puede ser interés de un acreedor internacional tener que verse en situaciones de esta naturaleza. La credibilidad en el Estado constituye el muro de prevención ante las adversidades que conlleva, generalmente, una inmovilización de importantes sumas de capital por incumplimiento de pagos.

En tales casos, señala el autor, existe una composición no uniforme de regímenes aplicables que se expresa tanto en áreas de penumbra en las cuales los criterios de decisión son imprecisos y de incipiente configuración jurídica, como en disciplinas colindantes que someten un mismo acto a decisiones distintas que operan bajo racionalidades distintas. Cuando un Estado deja de cumplir sus obligaciones financieras o amenaza hacerlo, desencadena reacciones contrarias por parte de los acreedores insatisfechos; los juristas van a tener dificultades considerables para comprender, por categorías normativas, algunas preguntas básicas y problemas mayores para ofrecer soluciones satisfactorias y permanentes. Asimismo, señala LOCHAGIN, que tal vacilación no discurre sólo por la ausencia de un cuadro regulatorio específico e inmediatamente identificable con parámetros sólidos sino que también se manifiesta en la imprecisión de reglas que permitan definir procedimientos y órganos competentes para dilucidar las controversias derivadas de la inejecución de las obligaciones financieras externas. No es que estas cuestiones sean ajenas al Derecho, sino que las reglas aplicables, cuando pueden ser identificadas, no constituyen un conjunto articulado y coherente.

18 LOCHAGIN, G. L. Elementos jurídicos da reestruturação internacional da dívida pública. Série Direito Financeiro, Conti, J. M. (Coord.). Blucher, Sao Paulo, 2017, p. 15. 
También se refiere el autor a la credibilidad del Estado. Señala que las situaciones en que las condiciones de pago de la deuda pública deben ser alteradas, ya sean caprichosas o necesarias, forzadas o voluntarias, implican el empeoramiento de las expectativas en cuanto a la credibilidad del Estado y el compromiso de su capacidad de atraer el crédito disponible, no raramente con sanciones económicas y políticas de otros Estados y de la generalidad de la comunidad financiera. En particular, en el caso de los acreedores privados, el pragmatismo frente a un deudor que interrumpe los pagos puede conducir a rápidas decisiones de retirada de inversiones, capaces de afectar el crédito público de tal manera que la mera posibilidad de las sanciones de exclusión de los mercados, impuestas espontáneamente por el propio mercado, sería capaz de inhibir la morosidad del Estado ${ }^{19}$.

El autor destaca asimismo que la resolución de conflictos de deuda pública externa se presenta bajo un contexto problemático caracterizado por una multiplicidad de agentes y normas aplicables. No se trata de una anarquía sino de una atomización que provoca la intercesión de regímenes no concatenados ${ }^{20}$. Este complejo panorama estimula que los inversionistas prefieran evitar el ejercicio de acciones jurídicas y con ello, dirigir sus inversiones hacia países que poseen una credibilidad inquebrantable.

\section{FACTORES PERMANENTES Y EVENTUALES INCIDEN EN LA CREDIBILIDAD}

La credibilidad puede ser enmarcada desde diversos puntos de vista, podemos distinguir entre credibilidad del país y la credibilidad del gobierno. La credibilidad del país se deriva de las condiciones inherentes a factores productivos o vocación productiva del país y las cuales forman parte de los procesos económicos permanentes. Aquí no se puede hablar solamente de la clase de actividades propias de un país sino también del volumen con el que las mismas se realizan. En los países monoproductores esta condición se convierte en determinante para su credibilidad en materia de endeudamiento público y es claramente identificable pues es reconocido en los círculos económicos tanto nacionales como internacionales. También es posible considerar la disponibilidad de recursos naturales que tiene un país aun cuando no hayan sido explotados, así sucede con el oro, diamante, minerales raros, entre otros, a largo plazo son la garantía de crecimiento económico, de la riqueza capaz de soportar el pago que el país deberá realizar de compromisos financieros, especialmente a nivel internacional.

La conexión internacional de una economía con otra, u otras, es inevitable en tiempos de globalización. Y más en círculos de deuda pública en los que las

19 Ídem, p. 16.

20 Ídem, pp. 17 y 19. 
plazas de inversión de deuda pública se centran en algunas bolsas de valores y cada país pasa a formar parte de un simple segmento del abanico de posibles inversiones. La diversificación económica entra a jugar un papel fundamental al garantizar que los riesgos en la producción no se basan en un solo elemento, en estos casos no es normalmente previsible que la misma se vea afectada de forma general por una misma causa. En estos términos, el crecimiento económico está relativamente garantizado y con ello se considera que el país tendrá la posibilidad de hacer frente a sus compromisos de deuda pública. Los factores eventuales en materia económica se asocian a aspectos que pueden incidir de manera no permanente en el crecimiento económico de un país; estos aspectos pueden incorporarse de forma definitiva a la vida económica de una nación.

Ahora bien, un inversionista no puede conocer de forma individualizada la información certera sobre esos factores permanentes y eventuales que inciden en la credibilidad como emisores de deuda pública. Pues de por sí, como afirma SÉRUZIER resulta difícil tener una medida de la situación económica de un país, "ya que son muy diversas las actividades de unos y otros", este conocimiento "constituye un desafío de la mayor importancia, en particular para los responsables de la política económica”, pero no sólo para ellos sino también "para todos los ciudadanos, comenzando por los hombres de negocios, cuya actividad depende en alguna medida de su entorno macroeconómico" 21.

De esta manera, los mercados de deuda pública deben ser objeto de estudio a partir de su sometimiento a una autoridad única encargada de las políticas financieras, es decir, si el país forma parte de un espacio de integración en el que una institución ha asumido estas riendas, esta entidad desplazará al país como centro de referencia, tal como sucede con la Unión Europea (UE) y el Banco Central Europeo (BCE). Caso contrario la unidad país representaría el punto de referencia, como sucede con los Estados Unidos de América (USA) y la Reserva Federal o un país latinoamericano y su respectivo banco central.

\section{LAS CIFRAS MACROECONÓMICAS SON DETERMINANTES}

La contabilidad nacional aparece así como "un instrumento de medición privilegiado al servicio de la ciencia económica" 22 , lo hace tanto a nivel microeconómico como a nivel macroeconómico. Los comportamientos individuales e interindividuales de los particulares no atañen a la deuda pública, tampoco los pre-

\footnotetext{
21 SÉRUZIER, M. Medir la economía de los países según el sistema de cuentas nacionales. CEPAL-Banco Central de Venezuela, Caracas, 2008, p. 1.

22 SÉRUZIER, M. Medir.., ob. cit., p. 2.
} 
cios y cantidades, lo que sí se encuentra vinculado a los fines de la credibilidad para el endeudamiento público es la macroeconomía.

La macroeconomía es definida por SAMUELSON y NORDHAUS como el "estudio del comportamiento de la economía como un todo. La macroeconomía examina las fuerzas que afectan simultáneamente a muchas empresas, consumidores y trabajadores". Su origen como ciencia, señalan los autores citados, "viene fundada por John Maynard Keynes al tratar de entender el mecanismo que condujo a la Gran Depresión”. Interesante la acotación que realizan sobre la consagración en los Estados Unidos de la Ley de Empleo de 1946 en la que "el Congreso confirmó la función del Estado en el estímulo del crecimiento del producto, la promoción del empleo y el mantenimiento de la estabilidad de precios" 23 . Con ello queremos resaltar que el papel del Estado es determinante en la economía aún en países considerados como de extremo liberal en materia económica, con ello se da paso a las políticas macroeconómicas tomadas dentro de un territorio que podemos considerar único a afectos de deuda pública.

Como objetivos de la política macroeconómica SAMUELSON y NORDHAUS, señalan la producción, el empleo y la estabilidad de los precios, y como instrumentos figuran la "política monetaria, controlar la oferta monetaria para determinar las tasas de interés” y la política fiscal, esto es, gasto público e impuestos $^{24}$. Ahora bien, la medida que mayor incidencia tiene en la credibilidad para acceder al crédito público es, sin duda, el Producto Interno Bruto (PIB), pues es el mejor reflejo de la economía de un país. Se trata de "la medida del valor de mercado de todos los bienes y servicios finales -cerveza, automóviles, conciertos de rock, paseos en burro, etc.- producidos en un año en un país" así lo definen SAMUELSON y NORDHAUS quienes acotan que como "medida de la producción más exactamente observada; funciona como el pulso, cuidadosamente vigilado, de la economía de un país". Estos autores consideran que "a pesar de las fluctuaciones de corta duración que se presentan en los ciclos económicos, las economías avanzadas generalmente muestran, en el largo plazo, un crecimiento continuo del PIB y un mejoramiento de los niveles de vida, proceso al que se le conoce como crecimiento económico" 25 . Un PBI en crecimiento es un gran incentivo para que un país acuda al endeudamiento público pues los inversionistas entienden que existe una mayor posibilidad de cumplimiento de la deuda pública y una mayor disponibilidad de divisas para hacer frente a compromisos internacionales.

23 SAMUELSON, P. y NORDHAUS, W. Economía..., ob. cit., p. 394.

${ }^{24}$ Ídem, p. 396.

25 Ídem. 
Si bien la correlación entre PIB-Deuda pública se ha incrementado vertiginosamente en la última década, por ahora no parece merecer mayor preocupación por parte de los bancos centrales y los inversionistas, siempre que exista crecimiento del PIB que garantice la continuidad de los pagos; como ya hemos señalado, el endeudamiento público es un fenómeno endémico en el siglo XXI. No obstante, si bien no puede hablarse de una estricta correlación PIB-deuda pública, se entiende que el endeudamiento público debe guardar una correlación con las cifras macroeconómicas a corto, mediano y largo plazo; un país no puede asumir deudas que sabe, de antemano, no tendrá la capacidad de cumplir debido a una proyección decreciente de su PIB. Esto debe ser considerado forzosamente por la legislación de cada país en el proceso de consideración sobre las emisiones de deuda y la cual debe ser total y absolutamente viable.

\section{CREDIBILIDAD Y ACCIÓN DE GOBIERNO}

Las políticas llevadas a cabo por un Gobierno nacional pueden contribuir a fomentar la credibilidad de un país en su acceso al endeudamiento público; no obstante, algunas de estas acciones no deben ser sobredimensionadas. Podemos señalar los instrumentos de la política macroeconómica tales como la política monetaria y la política fiscal.

Los gobiernos deben tomar todas las medidas necesarias para mantener su credibilidad como pagadores de las deudas que puedan llegar a asumir; y la mejor manera de hacerlo es pagando puntualmente sus obligaciones. La política de cumplimiento efectivo de la deuda pública se ha constituido en la manera más efectiva de convencer que un país tiene la condición de buen pagador, aún en tiempos difíciles para su crecimiento económico. Y ello es así porque si la deuda pública es un fenómeno endémico, las condiciones para que la misma se produzca deben ser celosamente cuidadas ante una reacción económica que pueda excluir al país de los círculos internacionales de inversionistas-Estados deudores. Se entiende que estas condiciones deben tener un carácter permanente, la estabilidad siempre es una garantía de pago para los inversionistas.

La deuda pública pasa a estar dramáticamente vinculada con el gasto público ya que si bien el Estado recibe dinero proveniente de los inversionistas y el cual destina a cubrir algunos de sus gastos, también debe incluir dentro de sus gastos anuales los vencimientos de tales deudas así como el pago de intereses; es así como el pago de la deuda pública se convierte en uno de los elementos que debe ser equilibrado dentro del presupuesto de una nación en correspondencia con los demás gastos. Ya hemos señalado que la deuda pública forma parte del entramado presupuestario. 
La doctrina plantea tres puntos de vista sobre la naturaleza de la actividad financiera del Estado. La económica, según la cual lo determinante son los conceptos económicos; la sociológica (PARETTO) que postula que las decisiones financieras vienen impuestas por una clase dominante según sus intereses particulares; finalmente, la política, debido a que en las decisiones financieras se da un predominio de los intereses del propio Estado, de sus fines, en una consideración que puede verse vinculada con elementos ideológicos ${ }^{26}$. Ahora bien, debemos plantearnos si según estas posturas un gobierno puede llegar a no priorizar el pago de la deuda pública dentro del gasto público. La respuesta fáctica es no, como principio general, los gobiernos siempre pagan la deuda pública aún a costa de recortes significativos en materia social; la excepción es cuando no lo hace. La historia de las últimas décadas ha demostrado que ello ocurre en situaciones macroeconómicas extremas como fue la crisis de deuda argentina.

Desde el punto de vista conceptual tampoco tendría sentido dejar de pagar la deuda como acto voluntario del Estado pues el endeudamiento público posee un carácter ordinario y todos los gobiernos acuden al mismo. Aún cuando se puede dar preferencia a cualquiera de las teorías señaladas, el resultado es el mismo, esto es, el país no puede perder su credibilidad en materia de deuda pública pues esta actividad forma parte de sus actividades financieras habituales. Adquiere gran importancia la opinión de los bancos centrales y el papel desempañado por los órganos legislativos encargados de aprobar las operaciones de financiamiento, especialmente cuando se está en el último año de un período de gobierno.

\section{LOS ALIADOS SON IMPORTANTES}

Resulta curioso que al margen de los aspectos anteriormente expuestos, un país que se encuentre carente de credibilidad para acudir al endeudamiento público pueda ver cambiar su panorama de forma extrema y pasar a ser un deudor con amplio respaldo financiero. El accionar de un actor financiero internacional puede ser determinante para que un país pueda equilibrar sus finanzas y hacer frente a otros compromisos internacionales; se debe advertir que estos actores tienen diversos intereses, el más importante es mantener la estabilidad del sistema financiero internacional para que no se produzca un efecto dominó ante el incumplimiento de un país deudor. Así, la falta de credibilidad de un país para cumplir con la deuda pública se puede multiplicar, el pánico apoderarse de los mercados y traer consecuencias ampliamente riesgosas para la economía mundial.

${ }^{26}$ En nuestro obra SUÁREZ, L. J. A., Ingreso..., ob. cit., pp. 24 y ss., hacemos referencias a estas escuelas y la bibliografía al respecto. 
De modo que, como hemos subtitulado este apartado de forma irónica y poco jurídica, los aliados son importantes. Contrario sensu si el país no posee una importancia relevante, ningún actor relevante en la comunidad financiera internacional prestará el apoyo necesario para recuperar la credibilidad. Aparecen así instituciones como el Fondo Monetario Internacional (FMI), el Banco Mundial (BM) y el Banco Central Europeo (BCE); asimismo, la pérdida del apoyo brindado por estas instituciones podría traer resultados nefastos para la credibilidad de un país, aunque no tendría que ser así necesariamente. Los inversionistas pueden mantener la credibilidad en el país aún cuando el mismo no disfrute del beneplácito de estas instituciones, obedeciendo a los aspectos señalados supra en la presente investigación.

Pero no podemos dejar de reiterar que los intereses de un actor internacional no tienen que ser necesariamente económicos; también pueden obedecer a aspectos geoestratégicos. En la actualidad, nos ubicamos en la agenda de las grandes potencias y su papel actual en la escena internacional o su proyección a futuro, tal como sucede con Rusia y China; desde luego que en aras de mantener su hegemonía, los Estados Unidos de América (USA) y sus aliados deben brindar los mecanismos de auxilio convenientes a países en situación crítica, pero también negarla a quienes se oponen al mismo. RESTREPO hace referencia a antecedentes históricos en los cuales el empréstito estuvo asociado a fines políticos y para ellos nos remite hasta la "época que transcurre hasta finales del siglo XVIII" en la que los grandes financistas de las coronas europeas llegaron a tener un notable poder político ${ }^{27}$.

Las sanciones impuestas por países como los Estados Unidos de América (USA) limitan jurídicamente la posibilidad de un país de acudir a los mercados internaciones tradicionales de deuda pública, tal como sucede actualmente con el caso de Venezuela. Los inversionistas pueden tener la confianza de pago a largo plazo y podrían estar dispuestos a invertir en su deuda pública, no obstante, se deben abstener de invertir, a los efectos de no ser objeto de sanción por parte de las autoridades financieras estadounidenses.

\section{CONCLUSIONES}

La credibilidad constituye un concepto que excede del plano jurídico, no obstante, es un presupuesto indispensable para el funcionamiento de la deuda pública. No es posible establecer una regulación normativa al respecto pues la misma es el resultado de un conjunto de factores de diferente naturaleza, especialmente aquellos que resultan de la política monetaria y fiscal.

27 RESTREPO, J. C. Hacienda..., ob. cit., p. 289. 
Sin la existencia de credibilidad a favor de un ente público, las figuras jurídicas diseñadas al respecto pueden quedar carentes de toda pertinencia. Se convive así con figuras mixtas de procedencia tanto jurídica como económica, estas últimas revestidas de elementos no siempre definidos de forma clara y precisa. La fuerza de los mercados puede llegar a asumir lo que el Derecho no es capaz de regular en materia internacional.

\section{BIBLIOGRAFÍA}

BANCO DE ESPANA. Administraciones Públicas. Deuda según el protocolo de déficit excesivo (PDE). [Disponible on line: www.bde.es/webbde/es/estadis/infoest /e0602.pdf], 2018.

BAQUERO, J. L. Lecciones de Finanzas Públicas y Derecho Fiscal, t. I, Paredes Editores, Caracas, 1989.

CONTRERAS DE USSCHER, I. Glosario y formulario de Administración Financiera. Universidad de Los Andes, Mérida, 2005.

DIEZ DE VELASCO, M. Instituciones de Derecho Internacional Público. Tomo I. $4^{\mathrm{a}}$ ed. Tecnos, Madrid, 1978.

DUVERGER, M. Hacienda Pública, 2ª ed. (trad. Bagaria Perpiñá). Bosch, Barcelona, 1980.

EHEBERG, K. T. Compendio de Hacienda Pública (trad. Ruiz Koenig). Editorial América, México, 1945.

LOCHAGIN, G. L. Elementos jurídicos da reestruturação internacional da dívida pública. Série Direito Financeiro, Conti, J. M. (Coord.). Blucher, Sao Paulo, 2017.

ORIA, S. Finanzas. Editorial Guillermo Kraft Ltda., Buenos Aires, 1948.

REAL ACADEMIA ESPAÑOLA. Diccionario de la Lengua Española. Edición del Tricentenario. [Disponible on line: www.rae.es], actualización 2017.

RESTREPO, J. C. Hacienda Pública, $3^{\mathrm{a}}$ ed. Universidad Externado de Colombia, Bogotá, 1996.

SAINZ DE BUJANDA, F. Lecciones de Derecho Financiero. Universidad Complutense, Madrid, 1993.

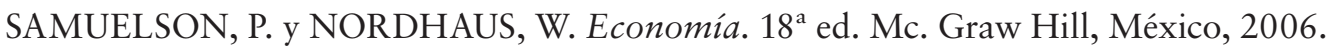
SÉRUZIER, M. Medir la economía de los países según el sistema de cuentas nacionales. CEPAL-Banco Central de Venezuela, Caracas, 2008.

SUÁREZ, L. J. A. El presupuesto público venezolano. Universidad de Los Andes, Mérida, 2012.

SUÁREZ, L. J. A. Ingreso, gasto y presupuesto público en el ordenamiento jurídico venezolano. Tomo I. Editor-autor, Mérida, 2011.

VILLEGAS, H. Curso de finanzas, derecho financiero y tributario. $5^{\mathrm{a}}$ ed. Depalma, Buenos Aires, 1992. 